\title{
TRIAGEM FITOQUÍMICA E AVALIAÇÃO DE PROPRIEDADES BIOLÓGICAS DO EXTRATO ALCOÓLICO DAS FOLHAS DE Eugenia pyriformis CAMBESS. (MYRTACEAE)
}

\author{
Yuri Lisik da Silva ${ }^{1}$ \\ Orlando Seiko Takemura ${ }^{1}$ \\ Sandra Regina da Silva Reis dos Santos ${ }^{2}$ \\ Mariza Barion Romagnolo ${ }^{3}$ \\ Antonio Laverde Junior ${ }^{4,5 *}$
}

\begin{abstract}
SILVA, Y. L. da; TAKEMURA, O. S.; SANTOS, S. R. da S. R. dos; ROMAGNOLO, M. B.; LAVERDE JUNIOR, A. Triagem fitoquímica e avaliação de propriedades biológicas do extrato alcoólico das folhas de Eugenia pyriformis Cambess. (Myrtaceae). Arq. Cienc. Saúde UNIPAR, Umuarama, v. 19, n. 3, p, 205-211, set./dez. 2015.

RESUMO: O extrato alcoólico (EUFO) das folhas da espécie nativa Eugenia pyriformis Cambess (Myrtaceae), popularmente conhecida como uvaia, uvalha ou uvaieira, foi avaliado no presente trabalho quanto às atividades citotóxicas, antioxidantes, antibacterianas e anticolinesterásicas, e quanto à constituição fitoquímica. O extrato EUFO mostrou baixa toxicidade pelo bioensaio de letalidade frente à náuplios de Artemia salina Leach $\left(\mathrm{CL}_{50}>1000 \mu \mathrm{g} \mathrm{mL} \mathrm{L}^{-1}\right)$, não sendo considerado citotóxico. As propriedades antioxidantes foram investigadas in vitro pelo método de $\mathrm{DPPH}$ e foram consideradas bastante significativas $\left(\mathrm{IC}_{50}=2,8 \mu \mathrm{g} \mathrm{mL}^{-1}\right.$ ), com valor bem próximo ao obtido para o controle positivo quercetina $\left(\mathrm{IC}_{50}=1,1 \mu \mathrm{g} \mathrm{mL}-1\right)$. EUFO não mostrou atividade anticolinesterásica pelo ensaio enzimático de inibição de acetilcolinesterase, nem atividade antimicrobiana frente às bactérias Escherichia coli e Staphylococcus aureus. Estes resultados sugerem que as folhas E. pyriformis apresentam baixa toxicidade e possuem componentes com elevado potencial antioxidante, especialmente taninos e flavonoides, podendo ser indicadas em terapias de doenças relacionadas com a presença de radicais livres.
\end{abstract}

PALAVRAS-CHAVE: Eugenia pyriformis; Uvaia; Myrtaceae; Antioxidante.

\section{PHYTOCHEMICAL SCREENING AND EVALUATION OF BIOLOGICAL PROPERTIES OF ALCOHOLIC EXTRACT OF Eugenia uvalha Cambess. (Myrtaceae) LEAVES}

\begin{abstract}
The alcoholic extract (EUFO) of leaves from the native species Eugenia uvalha Cambess (Myrtaceae), popularly known in Brazil as uvaia, uvalha or uvaieira, were evaluated in this study for the cytotoxic, antioxidant, antibacterial and anticholinesterase activities and phytochemical characterization. Its EUFO extract showed low toxicity by the lethality bioassay using Artemia salina Leach (LC50> $1000 \mu \mathrm{g} \mathrm{mL}^{-1}$ ) and it did not show cytotoxicity. The antioxidant properties were investigated by in-vitro DPPH method and found to be very significant $\left(\mathrm{CI}_{50}=2.8 \mu \mathrm{g} \mathrm{mL}^{-1}\right)$, very close to the value obtained for the positive control quercetin $\left(\mathrm{CI}_{50}=1.1 \mu \mathrm{g} \mathrm{mL}^{-1}\right)$. The EUFO did not show anticholinesterase activity by enzyme assay of acetylcholinesterase inhibition, or antimicrobial activity against Escherichia coli and Staphylococcus aureus. These results suggest that E. uvalha leaves present low toxicity and have presence of high potential antioxidant components, particularly tannins and flavonoids, which may be indicated in disease therapies associated with the presence of free radicals. This is the first report for the antioxidant activity of E. uvalha.
\end{abstract}

KEYWORDS: Eugenia uvalha; Myrtaceae; Uvaia; Antioxidant.

Introdução

No Brasil, há aproximadamente mil espécies de Myrtaceae, das quais cerca de um terço pertencem ao gênero Eugenia, um dos mais importantes desta família. Muitas espécies deste gênero se destacam pela produção de frutos de valor nutritivo, além de algumas serem utilizadas na medicina popular (GUPTA et al., 2014; OLIVEIRA et al., 2006; CRUZ; KAPLAN, 2004; ROMAGNOLO; SOUZA, 2004).

A espécie Eugenia pyriformis Cambess. (Myrtaceae) [sinonímia: E. uvalha Cambess.], conhecida como uvaia, uvalha ou uvaieira, ocorre principalmente na região entre os estados de São Paulo e Rio Grande do Sul, particularmente na floresta semidecídua do planalto e na bacia do rio Paraná (SOUZA; LORENZI, 2005). É uma espécie arbórea que atinge de 6 a 13 metros de altura, dotada de copa arredondada, flores solitárias e brancas (LORENZI, 2002). Os frutos, drupas globosas de cor amarela, são carnosos e comestíveis, sendo muito apreciados para o consumo na forma de sucos, sorvetes, geleias e doces (SCALON; SCALON; RIGONI, 2004). Os frutos também são muito procurados por várias espécies de pássaros, tornando essa espécie bastante útil em reflorestamentos de áreas degradadas de preservação permanente (LORENZI, 2002). Apesar dos frutos serem consumidos pelo homem, há um relato de caso recente associando a intoxicação de ovinos com a ingestão de frutos de uvaia (EMMERICH et al., 2014).

Ainda são poucos os estudos referentes às propriedades biológicas e composição química desta espécie. Estudos conduzidos por Pereira et al. (2012) e Ramirez et al.

DOI: https://doi.org/10.25110/arqsaude.v19i3.2015.5550

${ }^{1}$ Laboratório de Produtos Naturais, Instituto de Ciências Biológicas, Médicas e da Saúde, Universidade Paranaense, Praça Mascarenhas de Moraes, s/n, cx. p. 224, CEP 87502-210, Umuarama, PR, Brasil.

${ }^{2}$ Laboratório de Análises Clínicas, Instituto de Ciências Biológicas, Médicas e da Saúde, Universidade Paranaense, Praça Mascarenhas de Moraes, s/n, cx. p. 224, CEP 87502-210, Umuarama, PR, Brasil.

${ }^{3}$ Laboratório de Vegetação Ripária, NUPÉLIA, Departamento de Ciências Biológicas, Universidade Estadual de Maringá, Av. Colombo, 5790, CEP 87020900, Maringá, PR, Brasil.

${ }^{4}$ Programa de Mestrado em Biotecnologia Aplicada à Agricultura, Instituto de Ciências Exatas, Agrárias, Tecnológicas e Geociências, Universidade Paranaense, Praça Mascarenhas de Moraes, s/n, cx. p. 224, CEP 87502-210, Umuarama, PR, Brasil.

${ }_{5}^{5}$ Departamento de Química, Universidade Tecnológica Federal do Paraná, Campus Londrina, Avenida dos Pioneiros, 3131, CEP 86036-370, Londrina, PR, Brasil. (*correspondência: aljunior@utfpr.edu.br) 
(2012) relataram que extratos dos frutos de E. pyriformis apresentaram propriedades antioxidantes elevadas, além de atividade anti-inflamatória, sendo que o segundo grupo de autores observaram ambas atividades em modelos in vitro e in vivo. Salvador et al. (2011) também relataram atividade antioxidante para esta espécie, porém para extratos das folhas. Extratos das folhas, galhos, frutos e sementes de uvaia mostraram atividades antimicrobianas (CHAVASCO et al., 2014; STIEVEN, MOREIRA, SILVA, 2009). Segundo Assis et al. (2011), o óleo essencial das folhas de uvaia apresenta alta atividade acaricida frente à Tyrophagus putrescentiae (Schrank) e Suidasia pontifica Oudemans (Acari: Astigmata). Esses ácaros estão associados aos produtos armazenados (grãos, queijos, nozes, frutas secas, farinhas, etc.) e também podem causar reações alérgicas em humanos. Quanto à composição química, Stefanello et al. (2009) avaliaram a variação sazonal dos óleos essenciais das folhas da uvaieira e observaram que os mesmos são caracterizados por composição variada de mono e sesquiterpenos, tendo como principais componentes o pineno, limoneno, 1,8-cineol e o óxido de cariofileno. Os autores também avaliaram a composição dos óleos essenciais dos frutos e das flores desta espécie, onde observaram que o óxido de cariofileno (16.2\%) e o limoneno $(12.4 \%)$ foram os componentes majoritários no óleo dos frutos, enquanto que E-cariofileno (22.8\%) e germacreno D (15.3\%) foram os majoritários no óleo das flores. Alguns estudos indicam altos índices de carotenoides nos frutos, além de compostos fenólicos (PEREIRA et al., 2012; HAMINIUK et al., 2014; SILVA et al., 2014), os quais podem estar associados às propriedades antioxidantes.

Considerando a importância de ampliar o conhecimento a respeito de novas propriedades biológicas de espécies brasileiras nativas, o presente estudo buscou avaliar potenciais atividades da espécie Eugenia pyriformis Cambess. (Myrtaceae). Com esse propósito, o extrato alcoólico das folhas de uvaieira foi avaliado pelo método in vitro de inibição do radical livre estável 2,2-difenil-1-picrilidrazil (DPPH) quanto às propriedades antioxidantes, pelo bioensaio de letalidade frente à Artemia salina quanto à atividade citotóxica, pela técnica de difusão em disco para a avaliação da susceptibilidade antimicrobiana frente a bactérias de interesse clínico e pelo ensaio enzimático de inibição de acetilcolinesterase quanto à atividade anticolinesterásica. Além disso, foi realizada uma avaliação fitoquímica para a caracterização preliminar de alguns grupos de metabólitos secundários presentes no extrato em estudo.

\section{Materiais e Métodos}

\section{Material vegetal}

As folhas de uvaieira (Eugenia pyriformis Cambess.) foram coletadas em dezembro de 2010 numa área de reserva legal de floresta estacional semidecidual da Fazenda Santa Isabel, em Presidente Castelo Branco, PR, Brasil. O material vegetal foi identificado pela botânica Prof. ${ }^{\text {a }}$ Dr. ${ }^{a}$ Mariza Barion Romagnolo. Uma exsicata encontra-se depositada no Herbário Educacional da Universidade Estadual de Maringá, sob o registro nº HUEM 21663.

\section{Preparação dos extratos}

As folhas de E. pyriformis foram secas em estufa com circulação de ar (TECNAL) a $35^{\circ} \mathrm{C}$ e, posteriormente, pulverizadas em trituradores. A maior parte desse material foi submetida à maceração por exaustão em etanol, para a obtenção do extrato bruto das folhas (EUFO). O extrato etanólico resultante foi seco por evaporação sob pressão reduzida em evaporador rotativo (TECNAL) para total remoção do solvente, seguido de liofilização por 48h (LIOBRAS). O restante das folhas trituradas foi utilizado na realização de testes de caracterização fitoquímica dos componentes da planta.

\section{Caracterização fitoquímica}

Foram realizados testes analíticos a fim de verificar a presença dos principais grupos de metabólicos secundários (alcaloides, antraquinonas, cardiotônicos, flavonoides e taninos) presentes nas folhas da uvaieira. A metodologia utilizada foi adaptada de Costa (2001) e Matos (1997): reação de Borntraeger (método direto e extração por solvente) para caracterização de antraquinonas; teste de Lieberman-Bouchard e teste de Kedde para caracterização de cardiotônicos; reação de Shinoda e reação com cloreto de alumínio para caracterização de flavonoides; teste de Meyer e teste de Dragendorff para caracterização de alcaloides; e reação com gelatina, reação com acetado de chumbo e reação com sais de ferro para confirmação de taninos.

\section{Avaliação da atividade antimicrobiana}

A avaliação da susceptibilidade antimicrobiana de EUFO foi realizada por meio da técnica de difusão em disco, conforme descrito por Rabanal et al. (2002) e Karaman et al. (2003), aplicando $10 \mu \mathrm{L}$ da amostra do extrato ser testado em discos de papel filtro de $6 \mathrm{~mm}$ de diâmetro. Após a aplicação, os discos foram armazenados em estufa a $37^{\circ} \mathrm{C}$ até o momento da utilização para que o solvente utilizado na diluição da amostra fosse evaporado, a fim de evitar interferência nos resultados. O antibiograma foi realizado de acordo com a técnica de difusão em disco descrita por Bauer et al. (1966), usando placas de ágar Müller-Hinton (Merck) em que foram semeadas, pela técnica de varredura, as cepas de Escherichia coli ATCC 8739 e Staphylococcus aureus ATCC 6538, ambas de suspensões segundo a escala 0,5 de Mac-Farland. Foram então inseridos os discos de papel filtro impregnados com a amostra (diluição de $1000 \mu \mathrm{g} \mathrm{mL}^{-1}$ de EUFO), controle negativo (disco impregnado apenas com o solvente utilizado na diluição) e um disco controle positivo de cloranfenicol $30 \mu \mathrm{g}$. Em seguida, as placas foram incubadas a $37^{\circ} \mathrm{C}$ em estufa por um período de 24 horas e então foi realizada a leitura, medindo os halos bacterianos formados para determinar a concentração inibitória mínima (CIM).

\section{Avaliação da atividade anticolinesterásica}

A verificação da atividade anticolinesterásica foi avaliada por ensaio bioautográfico descrito por Yang et al. (2009) com algumas modificações (SILVEIRA et al., 2011). Inicialmente, o extrato EUFO foi aplicado em cromatoplaca de alumínio $\left(3 \times 10 \mathrm{~cm}\right.$, sílica Gel $60 \mathrm{~F}_{254}$ com 0,2 mm 
de espessura). Para a eluição da cromatoplaca foi utilizada uma mistura de diclorometano/metanol, na proporção de 9:1. Após a migração da amostra e secagem para eliminação dos solventes, a cromatoplaca foi borrifada primeiramente com uma solução (1U $\left.\mathrm{mL}^{-1}\right)$ de enzima liofilizada de acetilcolinesterase de peixe elétrico (EC 3.1.1.7, Sigma-Aldrich ${ }^{\circledR}$ ) dissolvida em solução tampão (Tris $0,05 \mathrm{M}, \mathrm{pH}$ 7,8 contendo $1 \mathrm{mg} \mathrm{mL}^{-1}$ de albumina de soro bovino - BSA, 98\%, Sigma-Aldrich $\left.{ }^{\circledR}\right)$, seguida de uma solução de acetato de $\alpha$-naftila (Sigma-Aldrich $®)$ dissolvida (1,5\%) em etanol PA/água. Uma secagem parcial foi realizada na placa, que foi mantida em banho-maria $\left(37^{\circ} \mathrm{C}\right)$ por 20 minutos. Após este período, a cromatoplaca foi borrifada com o reagente colorimétrico Fast Blue B (95\%, Sigma-Aldrich $\left.{ }^{\circledR}\right)$, que resulta na formação de uma coloração púrpura na superfície da cromatoplaca em poucos minutos. A ausência da coloração púrpura caracteriza a atividade anticolinesterásica, demonstrando a ação inibitória das substâncias presentes no extrato sobre a atividade da enzima.

\section{Avaliação da atividade citotóxica}

Para determinar a atividade citotóxica do extrato alcoólico das folhas de uvaieira foi utilizado o teste de letalidade frente à Artemia salina Leach (MEYER et al ., 1982) com pequenas modificações (MANETTI et al., 2010). Os ovos de A. salina foram incubados à temperatura ambiente por 48 horas em água do mar artificial $(38,0 \mathrm{~g}$ de sal marinho em 1,0 L de água deionizada) até a sua eclosão. Neste estágio inicial, as larvas, também conhecidas como náuplios, possuem fototropismo positivo, por isso foi utilizada uma fonte de luz artificial para atrair e facilitar a coleta. Dez náuplios foram transferidos para tubos de ensaio contendo 5,0 de $\mathrm{mL}$ água do mar artificial e o extrato dos frutos a ser testado em diferentes concentrações $(1000,500,250,125,62,5$ e $25 \mu \mathrm{g}$ $\mathrm{mL}^{-1}$ ). Após $24 \mathrm{~h}$ foi realizada a contagem dos náuplios mortos. Esse número foi usado para o cálculo da concentração letal para $50 \%$ das larvas $\left(\mathrm{CL}_{50}\right)$ empregando o método de Probitos. Os extratos com $\mathrm{CL}_{50}<1000 \mu \mathrm{g} \mathrm{mL} \mathrm{mL}^{-1}$ foram considerados ativos (MEYER et al., 1982). Como controle negativo utilizou-se água salina. Todos os ensaios foram realizados em triplicata.

\section{Avaliação da atividade antioxidante}

A atividade sequestradora de radical livre (atividade antioxidante) do extrato EUFO foi determinada na presença do radical livre estável 2,2-difenil-1-picrilidrazil (DPPH; Sigma-Aldrich®) (MOLYNEUX, 2004). Os experimentos foram realizados adicionando-se em cada tubo de ensaio 2,9 mL da solução metanólica de DPPH $(4,7 \mathrm{mg} / 200 \mathrm{~mL})$ e $100 \mu \mathrm{L}$ da solução metanólica de diferentes concentrações do extrato bruto. O extrato foi avaliado em concentrações decrescentes de $100,50,25,12.5,6.25,3.125$ e $1.56 \mu \mathrm{g} \mathrm{mL}^{-1}$. As leituras das absorbâncias $(515 \mathrm{~nm})$ foram realizadas em espectofotômetro (FEMTO, modelo 700 plus). Uma solução de quercetina $\left(100 \mu \mathrm{g} \mathrm{mL}^{-1}\right)$ foi utilizada como padrão positivo. Todas as análises foram realizadas em triplicata com repetição $(n=6)$ e apresentadas em porcentagem de inibição (\%), calculados em relação à amostra controle (metanol + DPPH $60 \mu \mathrm{M}$ ). Os desvios padrões foram dados em porcenta- gem de inibição. A atividade antioxidante foi calculada através da equação:

$$
\% \mathrm{DPPH}=[(\mathrm{Abs} \mathbf{C}-\mathrm{Abs} \mathbf{A}) * 100] /(\mathrm{Abs} \mathbf{C})
$$

Onde Abs $\mathbf{C}$ e Abs $\mathbf{A}$ correspondem às absorbâncias do controle e da amostra, respectivamente (MOLYNEUX, 2004).

\section{Resultados e Discussão}

\section{Triagem fitoquímica}

A triagem fitoquímica conduzida neste estudo avaliou a presença de diferentes classes de metabólitos no extrato alcoólico das folhas de E. pyriformis: alcaloides, antraquinonas, cardiotônicos, flavonoides e taninos. A prospecção fitoquímica evidenciou a presença de taninos e flavonoides. Ressaltando que os testes realizados foram de aspecto qualitativo, podendo resultar em falsos negativos caso os compostos pesquisados estejam em baixa concentração no extrato.

Os taninos são compostos fenólicos presentes nos metabólitos secundários de várias plantas, conhecidos por sua ação adstringente, explicada pela sua capacidade de precipitar proteínas, causando repulsa aos herbívoros e protegendo a planta. Como características farmacológicas, é relatada sua ação como anti-inflamatório, cicatrizante, anticarcinogênico e como redutor de radicais livres (MONTEIRO; ALBUQUERQUE; ARAÚJO, 2005).

Os flavonoides são compostos fenólicos presentes nos metabólitos secundários de várias plantas, e exercem diversas funções como pigmentação de frutos e flores, inibição enzimática, além de proteção da planta contra: incidência de raios ultravioletas, micro-organismos patógenos e oxidação. No ser humano é relatada a ação dos flavonoides como antioxidante, anti-inflamatório, vasodilatador, antialérgico, antimicrobiano e antiviral, sendo recomendável a ingestão in natura, pois o processamento dos alimentos pode degradar os compostos (LOPES et al., 2000; MACHADO et al., 2008). Os flavonoides são recomendados para a dieta humana, devido aos seus efeitos benéficos à saúde, como seu fator antioxidante, que ocorre devido sua ação sequestradora dos radicais livres, principalmente aqueles envolvidos diretamente com a peroxidação lipídica (BEHLING et al., 2004).

\section{Avaliação da atividade antioxidante}

A pesquisa de antioxidantes, compostos capazes de reduzir ou inibir a ação de radicais livres no organismo, é de grande importância para a saúde, pois o oxigênio, apesar de essencial para os seres vivos, é muito instável e pode causar sérios danos quando ocorre sua exposição em concentrações muito elevadas (BEHLING et al., 2004).

A avaliação das propriedades antioxidantes do extrato EUFO foi realizada pela técnica de redução do radical livre de DPPH. A partir dos dados obtidos, observou-se que o extrato das folhas de uvaieira alcançou níveis de inibição próximos ao do controle positivo utilizado (quercetina), como pode ser visualizado na Figura 1. 
Figura 1: Percentuais de inibição do radical livre de DPPH na presença de diferentes concentrações de E. pyriformis e do controle positivo, quercetina.

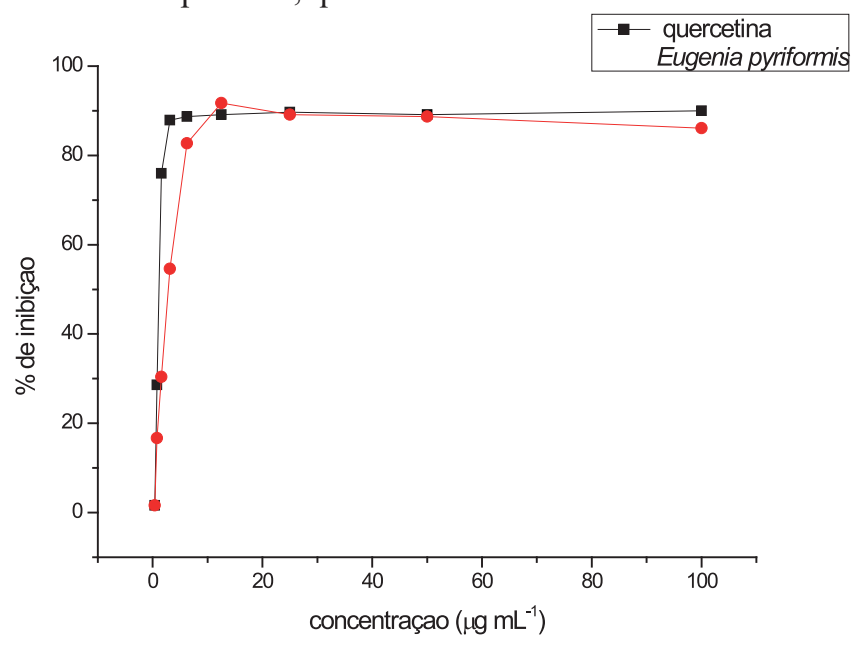

A concentração responsável pela inibição de 50\% do radical livre de DPPH $\left(\mathrm{IC}_{50}\right)$ foi calculada por meio do gráfico da Figura 1, resultando no valor de $2,8 \mu \mathrm{g} \mathrm{mL}^{-1}$. Este resultado foi bem próximo ao do obtido para o controle positivo quercetina $\left(\mathrm{IC}_{50}=1,1 \mu \mathrm{g} \mathrm{mL}^{-1}\right)$, sugerindo que as folhas de E. pyriformis apresentem componentes com elevado potencial antioxidante. Tal resultado também está bem próximo $\left(\mathrm{IC}_{50}=1,7 \mu \mathrm{g} \mathrm{mL}^{-1}\right)$ ao observado por SALVADOR et al. (2011) para as folhas de uvaia coletadas no Rio Grande do Sul. Comparando este resultado com outros da literatura para espécies do mesmo gênero, como a E. copacabanensis $\left(\mathrm{IC}_{50}=2,7 \mu \mathrm{g} \mathrm{mL}^{-1}\right)$ (CARVALHO JUNIOR et al., 2014), $E$. caryophyllata $\left(\mathrm{IC}_{50}=5,9 \mu \mathrm{g} \mathrm{mL}^{-1}\right)$ (YA et al., 2015), E. foetida $\left(\mathrm{IC}_{50}=15,9 \mu \mathrm{g} \mathrm{mL}^{-1}\right)(\mathrm{REYNERTSON}$; BASILE; KENNELLY, 2005) e E. uniflora $\left(\mathrm{IC}_{50}=19,6 \mu \mathrm{g} / \mathrm{ml}\right)$ (REYNERTSON; BASILE; KENNELLY, 2005), pode-se considerar que a E. pyriformis se destaca como uma espécie de potencial interesse como fonte de princípios ativos com propriedades antioxidantes.

Considerando que no ensaio fitoquímico do extrato das folhas de E. pyriformis foi detectada a presença de flavonoides e taninos, os quais são reconhecidos como potentes agentes antioxidantes, pode-se sugerir que o efeito antioxidante encontrado neste estudo possa estar diretamente relacionado à presença de substâncias dessas classes de compostos. Recentemente Haminiuk et al. (2014) relataram a presença de flavonoides (miricetina, quercetina e caempferol) e ácidos fenólicos (ácidos gálico e clorogênico) nos frutos de uvaia.

\section{Avaliação da atividade antimicrobiana}

A susceptibilidade antimicrobiana do extrato EUFO foi avaliada pelo método de difusão em disco frente a duas bactérias de interesse clínico, uma Gram-positiva (Staphylococcus aureus ATCC 6538) e uma Gram-negativa (Escherichia coli ATCC 8739). Os resultados obtidos estão descritos na tabela 1 .
Tabela 1: Avaliação da atividade antimicrobiana.

\begin{tabular}{cccc}
\hline Micro-organismos & EUFO & CN & CP \\
\hline Escherichia coli & 0,0 & 0,0 & $30 \mathrm{~mm}$ \\
Staphylococcus aureus & 0,0 & 0,0 & $27 \mathrm{~mm}$
\end{tabular}

EUFO: Extrato bruto das folhas de E. uvalha $\left(1000 \mu \mathrm{g} \mathrm{mL}^{-1}\right)$; CP: Controle Positivo (cloranfenicol, $30 \mu \mathrm{g}$ ); CN: Controle negativo.

Ao contrário de outros autores (STIEVEN, MOREIRA, SILVA, 2009; HOLETZ et al., 2002), o extrato das folhas $E$. pyriformis avaliado neste trabalho não apresentou potencial antimicrobiano para ambas bactérias utilizadas nesse trabalho. No presente trabalho, nenhuma das bactérias testadas se mostrou sensível ao extrato das folhas de uvaieira. Eventualmente, esse estudo poderia apresentar propriedades antimicrobianas frente a outros micro-organismos não testados. A espécie $E$. repanda também não apresentou nenhuma atividade inibitória frente a $E$. coli e $S$. aureus, porém foi ativa frente a outros micro-organismos como Listeria inocua, Mycobacterium tuberculosis, Candida albicans e Aspergillus niger (BERTUCCI et al., 2009).

A resistência da bactéria $E$. coli foi evidenciada em outras espécies da família Myrtaceae, como: E. mansoni, E. malaccensis, Myrtus communis e Psidium guajava. Apesar disto, todas estas espécies mostraram atividade frente a $S$. aureus e outros micro-organismos (SALVAGNINI et al., 2008; GOLÇALVES; ALVES FILHO; MENEZES, 2005; SANCHES et al., 2005; LOCHER et al., 1995).

\section{Avaliação da atividade citotóxica}

A atividade citotóxica do extrato foi avaliada pelo teste de letalidade frente ao microcrustáceo Artemia salina Leach. Trata-se de um bioensaio rápido, fácil e confiável para a determinação de toxicidade, uma vez que a grande maioria dos compostos bioativos é considerada tóxica em altas concentrações (MEYER et al ., 1982). Diversos estudos buscam correlacionar a toxicidade sobre a A. salina com atividades antifúngica, antimicrobiana, parasiticida, antiviral, entre outras (ALVES et al., 2000; SIQUEIRA et al., 1998; McLAUGHLIN; SAIZARBITORI; ANDERSON, 1995; MEYER et al., 1982). Além disso, existe uma correlação entre a toxicidade geral da $A$. salina e a citotoxicidade frente a linhagens de células humanas tumorais (McLAUGHLIN; SAIZARBITORI; ANDERSON, 1995; MEYER et al., 1982).

Meyer et al. (1982) classificaram extratos vegetais brutos como tóxico $\left(\mathrm{CL}_{50}<1000 \mu \mathrm{g} \mathrm{mL}^{-1}\right)$ ou atóxico $\left(\mathrm{CL}_{50}>\right.$ $\left.1000 \mu \mathrm{g} \mathrm{mL}^{-1}\right)$, de acordo com os níveis requeridos para atingir a $\mathrm{CL}_{50}$ nos ensaios de letalidade com $A$. salina. Baseado nesta classificação, o extrato das folhas de E. pyriformis não foi considerado citotóxico mostrando a $\mathrm{CL}_{50}$ maior que 1000 $\mu \mathrm{g} \mathrm{mL}^{-1}$. Pode-se concluir que esta espécie não apresenta substâncias com características citotóxicas em altas concentrações. Logo, a ausência de citotoxicidade observada pode ser um indicador de que a planta pode ser bem tolerada pelo sistema biológico. Entretanto, estudos mais detalhados para a avaliação da toxicidade deste extrato se fazem necessários empregando-se outros modelos (in vitro e in vivo). 


\section{Avaliação da atividade anticolinesterásica}

Outra atividade biológica avaliada no presente estudo foi a capacidade inibidora da enzima acetilcolinesterase (AChE). Os inibidores da AchE são utilizados no tratamento da doença de Alzheimer. Esta doença é uma desordem neurodegenerativa do cérebro, responsável por cerca de metade dos casos de demência dentre pessoas sexagenárias (VIEGAS JR et al., 2004). Dessa forma, a elevação do nível da acetilcolina pode se mostrar útil para amenizar a deficiência da aprendizagem, um dos sinais da doença (TREVISAN; MACEDO, 2003).

Nos ensaios realizados não foi observada a inibição da enzima acetilcolinesterase pelo extrato das folhas de $E$. pyriformis. Segundo levantamento bibliográfico, ainda poucas espécies da família Myrtaceae foram relatadas apresentando esta atividade, dentre elas as espécies Psidium guajava (GUPTA; GUPTA, 1997), Callistemon lanceolatus (GUPTA; GUPTA, 1997; PARK et al., 2010), Syzygium jambolana (MAZZANTI et al., 2004), Marlierea racemosa (SOUZA et al., 2009), Eugenia riedeliana (SOUZA et al., 2010), Myrceugenia myrcioides (SOUZA et al., 2010), Cleistocalyx operculatus (MIN et al., 2010), Myrcianthes pungens (SILVEIRA et al., 2011).

\section{Conclusão}

Entre as atividades avaliadas neste estudo, a capacidade sequestradora de radicais livres do extrato alcoólico das folhas de E. pyriformis foi a mais importante, mostrando uma atividade antioxidante bastante intensa, com valores muito próximos ao do padrão empregado. Considerando o perfil fitoquímico identificado, poder-se-ia correlacionar a capacidade de sequestrar radicais livres observada a presença de compostos fenólicos, especificamente flavonoides e taninos, uma vez que essas classes de compostos são reconhecidas por suas propriedades antioxidantes.

O extrato avaliado também mostrou baixa toxicidade frente à Artemia salina $\left(\mathrm{CL}_{50}>1000 \mu \mathrm{g} \mathrm{mL} \mathrm{L}^{-1}\right)$, resultado que pode ser um indicador de que a planta pode ser bem tolerada pelo sistema biológico. Contudo, estudos mais detalhados para a avaliação da toxicidade e capacidade antioxidante deste extrato se fazem necessários empregando-se outros modelos (in vitro e in vivo).

\section{Agradecimentos}

Nossos agradecimentos à Universidade Paranaense (UNIPAR) pelo apoio financeiro recebido (Projeto 20152/2011). Y.L.S. agradece à Diretoria Executiva de Gestão da Pesquisa e da Pós-Graduação (DEGPP) pela bolsa PIBIC de iniciação científica.

\section{Referências}

ALVES, T. M. D. et al. Biological screening of Brazilian medicinal plants. Mem. Inst. Oswaldo Cruz, v. 95, p. $367-$ 373,2000

ASSIS, C.P.O. et al. Toxicity of essential oils from plants towards Tyrophagus putrescentiae (Schrank) and Suidasia pontifica Oudemans (Acari: Astigmata). J. Stored Prod. Res., v. 47, p. 311-315, 2011.

BAUER, A. L. et al. Antibiotic susceptibility testing by a standardized single disk method. Amer. J. Clin. Pathol., v. 45, p. 493-496, 1966

BEHLING, E. B. et al. Flavonoide quercetina: aspectos gerais e ações biológicas. Alim. Nutr., v. 15, n. 3, p. 285 292, 2004.

BERTUCCI, A. et al. Initial antimicrobial activity studies of plants of the riverside forests of the Southern Uruguay River. Braz. J. Pharmacogn., v. 19, n. 1A, 2009.

CARVALHO JUNIOR, A. R. et al. Constituintes químicos e atividade antioxidante de folhas e galhos de Eugenia copacabanensis Kiaersk (Myrtaceae). Quim. Nova, v. 37 , n. 3, p. 477-482, 2014.

CHAVASCO J.M. et al. Evaluation of antimicrobial and cytotoxic activities of plant extracts from Southern Minas Gerais Cerrado. Rev. Inst. Med. Trop. Sao Paulo, v. 56, n. 1, p. 13-20, 2014

COSTA, A. F. Farmacognosia: farmacognosia experimental. 3. ed. v. 3. Lisboa: Calouste Gulbenkian, 2001.958 p.

CRUZ, A. V. M.; KAPLAN, M. A. C. Medicinal uses of species from Myrtaceae and Melastomataceae families in Brazil. Floresta e Ambiente, v. 11, n. 1, p. 47-52, 2004.

EMMERICH, T. et al. Intoxicação espontânea e experimental por frutos de Eugenia uvalha Cambess.

(Myrtaceae) em ovinos. Pesq. Vet. Bras., v. 34, n. 5, p. 438442, 2014.

GOLÇALVEZ, A. L.; ALVES FILHO, A.; MENEZES, H. Estudo comparativo da atividade antimicrobiana de extratos de algumas árvores nativas. Arq. Inst. Biol., v. 72, n. 3, p. 353-358, 2005.

GUPTA, A. et al. Biological importance of phytochemical constituents isolated from genus Eugenia. J. Indian Chem. Soc., v. 91, n. 8, 1539-1553, 2014.

GUPTA, A.; GUPTA, R. A survey of plants for presence of cholinesterase activity. Phytochemistry, v. 46, n. 5, p. 827831, 1997.

HAMINIUK, C. W. I. et al. Extraction and quantification of phenolic acids and flavonols from Eugenia pyriformis using different solvents. J. Food Sci. Technol., v. 51, n. 10, p. 2862-2866, 2014.

HOLETZ, F. B. et al. Screening of some plants used in the Brazilian folk medicine for the treatment of infectious diseases. Mem. Inst. Oswaldo Cruz, v. 97, n. 7, p. 10271031, 2002. 
KARAMAN, I. et al. Antimicrobial activity of aqueous and methanol extracts of Juniperus oxycedrus L. J.

Ethnopharmacol., v. 85, p. 231-235, 2003.

LOCHER, C. P. et al. Anti-microbial activity and anticomplement activity of extracts obtained from selected Hawaiian medicinal plants. J. Ethnopharmacol., v. 49, p. 23-32, 1995.

LOPES, R. M. et al. Farmacologia de flavonoides no controle hiperlipidêmico em animais experimentais. Biotec. Ciênc. Desenv., v. 3, n. 17, p. 18-22, 2000.

LORENZI, H. Árvores brasileiras: manual de identificação e cultivo de plantas arbóreas nativas do Brasil. 2. ed., v. 2. Nova Odessa: Instituto Plantarum de Estudos da Flora, 2002.

MAZZANTI, C. M. et al. Efeito do extrato da casca de Syzygium cumini sobre a atividade da acetilcolinesterase em ratos normais e diabéticos. Ciênc. Rural, v. 34, n. 3, p. 803-807, 2004.

MANETTI, L. M. et al. Avaliação das atividades antimicrobiana, citotóxica, moluscicida e antioxidante de Bromelia antiacantha Bertol. (Bromeliaceae). Rev. Bras. Pl. Med., v. 12, n. 4, p. 406-413, 2010.

MATOS, F. J. A. Introdução a fitoquímica experimental. 2. ed. Fortaleza: Edições UFC, 1997. 141 p.

McLAUGHLIN, J. L.; SAIZARBITORI, T. C.;

ANDERSON, J. E. Tres bioensayos simples para químicos de productos naturales. Rev. Soc. Venez. Quím., v. 18, p. 13-18, 1995.

MEYER, B. N. et. al. Brine shrimp: a convenient general bioassay for active plant constituents. Planta Med., v. 45, n. 5, p. 31-34, 1982.

MIN, B.S. et al. Cholinesterase inhibitors from Cleistocalyx operculatus buds. Arch. Pharmacal Res., 33, 10, 16651670, 2010.

MOLYNEUX P. The use of the stable free radical diphenylpicryl-hydrazyl (DPPH) for estimating antioxidante activity. Songklanakarin J. Sci. Technol., v. 26, n. 2, p. 211-219, 2004.

MONTEIRO, J. M; ALBUQUERQUE, U. P; ARAÚJO, E. L. Taninos: uma abordagem da química à ecologia. Quím. Nova, v. 28, n. 5, p. 892-696, 2005.

OLIVEIRA, A. M. et al. Estudo fitoquímico e avaliação das atividades moluscicida e larvicida dos extratos da casca do caule e folha de Eugenia malaccensis L. (Myrtaceae). Rev. Bras. Farmacogn., v. 16, p. 618-624, 2006.

PARK, S.-Y. et al. C-Methylflavonoids isolated from Callistemon lanceolatus protect $\mathrm{PC} 12$ cells against $\mathrm{A} \beta$ induced toxicity. Planta Med., v. 76, n. 9, p. 863-868, 2010.
PEREIRA, M. C. et al. Characterization and antioxidant potential of Brazilian fruits from the Myrtaceae family. J. Agric. Food Chem., v. 60, p. 3061-3067, 2012.

RABANAL, R. M. et al. Antimicrobial studies on three species of Hypericum from the Canary Islands. J. Ethnopharmacol., v. 81, p. 287-292, 2002.

RAMIREZ, M. R. et al. Evaluation of the polyphenolic content, anti-inflammatory and antioxidant activities of total extract from Eugenia pyriformes Cambess (uvaia) fruits. J. Food Biochem., v. 36, n. 4, p 405-412, 2012.

REYNERTSON, K. A.; BASILE, M. J.; KENNELLY, E. J. Antioxidant potential of seven Myrtaceous fruits. Ethnobot. Res. Appl., v. 3, p. 25-35, 2005.

ROMAGNOLO, M. B.; SOUZA, M. C. O gênero Eugenia L. (Myrtaceae) na planície de alagável do Alto Rio Paraná, Estados de Mato Grosso do Sul e Paraná, Brasil. Acta Botanica Brasilica, v. 20, n. 3, p. 529-548, 2006.

SALVADOR, M. J. et al. Antioxidant capacity and phenolic content of four Myrtaceae plants of the South of Brazil.

Nat. Prod. Commun., v. 6, n. 7, 977-982, 2011.

SALVAGNINI, L. E. et al. Avaliação da Atividade Antibacteriana de folhas de Myrtus communis L. (Myrtaceae). Rev. Bras. Farmacogn., v. 18, n. 2, p. 241244, 2008.

SANCHES, N. R. et al. An Evaluation of Antibacterial Activities of Psidium guajava (L.). Braz. Arch. Biol. Technol., v. 48, n. 3, p. 429-436, 2005.

SCALON, S. P. Q.; SCALON FILHO, H.; RIGONI, M. R. Armazenamento e germinação de sementes de uvaia Eugenia uvalha Cambess. Ciênc. Agrotec., v. 28, n. 6, p. 1228-1234, 2004.

SILVA, N. A. et al. Phenolic compounds and carotenoids from four fruits native from the Brazilian Atlantic Forest. J. Agric. Food Chem., v. 62, p. 5072-5084, 2014.

SILVEIRA, S. et al. Atividade anticolinesterásica dos frutos de Myrcianthes pungens (O.Berg.) D.Legrand (Myrtaceae). Arq. Ciênc. Saúde Unipar, v. 15, n. 2, p. 127-133, 2011.

SIQUEIRA, J. M. et al. Estudo fitoquímico de Unonopsis lindmanii - Annonaceae, biomonitorado pelo ensaio de toxicidade sobre a Artemia salina leach. Quim. Nova, v. 21, p. 557.1998.

SOUZA, A. et al. Chemical composition and acetylcholinesterase inhibitory activity of essential oils of Myrceugenia myrcioides (Cambess.) O. Berg and Eugenia riedeliana O. Berg, Myrtaceae. Rev. Bras. Farmacogn., v. 20, n. 2, p. 175-179, 2010.

SOUZA, A. et al. Differential acetyl cholinesterase inhibition by volatile oils from two specimens of Marlierea 
racemosa (Myrtaceae) collected from different areas of the Atlantic Rain Forest. Nat. Prod. Commun., v. 4, n. 8, p. 1143-1146, 2009.

SOUZA, V. C; LORENZI, H. Botânica Sistemática: Guia ilustrado para identificação das famílias de Angiospermas da flora brasileira. Nova Odessa: Instituto Plantarum de estudos da flora, 2005. 640 p.

STEFANELLO, M. E. A. et al. Chemical composition and seasonal variation of essential oils of Eugenia pyriformis (Myrtaceae). Latin Am. J. Pharm., v. 28, n. 3, p. 449-453, 2009 .

STIEVEN, A. C.; MOREIRA, J. J. S.; SILVA, C. F. Óleos essenciais de uvaia (Eugenia pyriformis Cambess.): avaliação das atividades microbiana e antioxidante. Eclet. Quím., v. 34, n. 3, p. 7-13, 2009.

TREVISAN, M. T. S.; MACEDO, F. V. V. Seleção de plantas com atividade anticolinasterase para tratamento da doença de Alzheimer. Quim. Nova, v. 26, p. 301, 2003.

VIEGAS JR., C. et al. Produtos naturais como candidatos a fármacos úteis do mal de Alzheimer. Quim. Nova, v. 27, p. 655-660, 2004

YA, W. et al. Preliminary screening of 44 plant extracts for anti-tyrosinase and antioxidant activities. Pak. J. Pharm. Sci., v. 28, n. 5, p.1737-1744, 2015.

YANG Z. et al. Modified TLC bioautographic method for screening acetylcholinesterase inhibitors from plant extracts. J. Separation Sci., v. 32, n. 18, p. 3257-3259, 2009. 